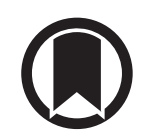

CrossMark

\title{
How to define pulmonary hypertension due to left heart disease
}

To the Editor:

Current 2015 European Society of Cardiology (ESC)/European Respiratory Society (ERS) guidelines for the diagnosis and treatment of pulmonary hypertension $(\mathrm{PH})[1,2]$ have adopted new insights in the understanding of $\mathrm{PH}$ due to left heart disease (PH-LHD, group 2).

The new guidelines present two subsets of PH-LHD: 1) isolated post-capillary PH (Ipc-PH), previously labelled as "passive" PH-LHD, defined by a mean pulmonary artery pressure (PAP) $\geqslant 25 \mathrm{mmHg}$, mean pulmonary artery wedge pressure (PAWP) $>15 \mathrm{mmHg}$, diastolic pulmonary vascular pressure gradient (DPG) $<7 \mathrm{mmHg}$ and/or pulmonary vascular resistance (PVR) $\leqslant 3$ Wood units (WU); and 2) combined post- and pre-capillary $\mathrm{PH}(\mathrm{Cpc}-\mathrm{PH})$, previously labelled as "reactive" or "out of proportion" $\mathrm{PH}-\mathrm{LHD}$, defined by a mean PAP $\geqslant 25 \mathrm{mmHg}$, mean PAWP $>15 \mathrm{mmHg}$, DPG $\geqslant 7 \mathrm{mmHg}$ and/or PVR $>3 \mathrm{WU}[1,2]$.

However, the previous definition of PH-LHD and the associated terminology of "passive" and "reactive" or "out-of-proportion" PH-LHD have been unsatisfactory for the characterisation of patients. Transpulmonary pressure gradient (TPG) is sensitive to changes in cardiac output, recruitment and distension of pulmonary vessels decreasing upstream transmission of left atrial pressure. Furthermore, pulmonary blood flow is pulsatile with systolic PAP and mean PAP, determined by stroke volume and arterial compliance [3-5]. At the fifth World Symposium on Pulmonary Hypertension in Nice, France, in 2013 and in the recently published ESC/ERS guidelines for the diagnosis and treatment of $\mathrm{PH}$, the definition of PH-LHD was revised $[1,2,5]$, mainly based on the observations that DPG is less flow dependent and less sensitive to elevation of left atrial pressure than TPG [4], and reflects pulmonary vascular remodelling [6].

Despite initial disagreement with DPG as a prognostic indicator $[7,8]$, the predictive value of DPG $\geqslant 7 \mathrm{mmHg}$ in PH-LHD has been confirmed by other groups in the meantime [9-12].

We would like to support the guideline PH-LHD classification. In a recent manuscript we have clarified that Cpc-PH (mean PAP $>15 \mathrm{mmHg}$ and DPG $\geqslant 7 \mathrm{mmHg}$ ) [13] is truly a distinct entity. We are demonstrating that $\mathrm{Cpc}-\mathrm{PH}$ is occurring in $\sim 12-13 \%$ of systolic heart failure and diastolic heart failure cases [13]. Cpc- $\mathrm{PH}$ is associated with a worse prognosis compared to Ipc-PH in both heart failure subsets [13]. To substantiate that DPG is relevant we have demonstrated a continuous impact of increasing DPG on the pulmonary vascular resistance (PVR)-compliance (CPA) relationship with a downward-rightward shift, illustrating that heart failure patients with higher DPGs have higher right ventricular (RV) afterload [13]. Interestingly, PVR-CPA relationship in Cpc- $\mathrm{PH}$ is similar to that in idiopathic pulmonary arterial hypertension [13]. RV to pulmonary vascular (RV-PV) coupling is worse in patients with $\mathrm{Cpc}-\mathrm{PH}$ than in Ipc-PH, possibly explaining our previous findings that survival is significantly shorter in $\mathrm{Cpc}-\mathrm{PH}[6,13]$. These data illustrate that $\mathrm{Cpc}-\mathrm{PH}$ represents heart failure patients with decreased RV function and pulmonary arteriopathy.

However, there is a problem with the diagnostic criteria of the new classification. The new guidelines bring PVR into the definition. According to our data, a stratification using a PVR $\geqslant 3 \mathrm{WU}$ did not provide prognostic implications [6]. In our database, PH-LHD patients with DPG $<7 \mathrm{mmHg}$ and PVR $>3 \mathrm{WU}(\mathrm{n}=76)$ had preserved RV-PV coupling (end-systolic elastance (Ees); arterial elastance (Ea) mean \pm SD 1.4 \pm 0.3 ) while RV-PV coupling was poor in those with DPG $\geqslant 7 \mathrm{mmHg}$ and PVR $>3 \mathrm{WU}(\mathrm{n}=41$; Ees/Ea mean \pm SD $1.1 \pm 0.3$, $\mathrm{p}<0.001$ ). We acknowledge that MiLleR et al. [14] demonstrated that prognosis was worse when PVR was $\geqslant 3$ WU. However, MilLeR et al. [14] only analysed heart failure patients with reduced ejection fraction, excluding patients who had heart failure with preserved ejection fraction and valvular heart disease. Furthermore, in contrast to our study [6], a TPG $>12 \mathrm{mmHg}$ was not predictive of outcome in the study by Miller et al. [14].

Using the discriminative term of and/or PVR $>3 \mathrm{WU}$ for the definition of both Ipc-PH and Cpc- $\mathrm{PH}$, one discovers that almost $30 \%$ of patients with PH-LHD fall into both categories (table 1). For example, a patient with PH-LHD and DPG of $6 \mathrm{mmHg}$ but a PVR of $4 \mathrm{WU}$ could be classified as having Ipc-PH (DPG $<7 \mathrm{mmHg}$ ) and as having Cpc-PH (PVR >3 WU). On the background of our 1506 patients with PH-LHD, 28.7\% of PH-LHD patients were unclassifiable using the guideline definition (table 1). 
TABLE 1 Patients with pulmonary hypertension (PH) due to left heart disease $(n=1506$, mean pulmonary artery pressure $\geqslant 25 \mathrm{mmHg}$, and mean pulmonary artery wedge pressure $>15 \mathrm{mmHg}$ ) stratified by diastolic pulmonary vascular pressure gradient (DPG) and pulmonary vascular resistance (PVR)

\begin{tabular}{lcc} 
& DPG $<7 \mathrm{mmHg}$ & DPG $\geqslant 7 \mathrm{mmHg}$ \\
\hline PVR $\leqslant 3$ WU $\mathrm{n}(\%)$ & $858(57.0)^{\#}$ & $\mathbf{4 4}(2.9)$ \\
PVR $>3$ WU $\mathrm{n}(\%)$ & $388(25.8)$ & $216(14.3)^{\pi}$
\end{tabular}

Numbers in bold indicate the number of patients (432 (28.7\%)) with DPG/PVR combinations that are unclassifiable using the current definition of the 2015 European Society of Cardiology and the European Respiratory Society guidelines [1, 2]. WU: wood units. \#: isolated post- and pre-capillary PH with DPG $<7 \mathrm{mmHg}$ and/or PVR $\leqslant 3 \mathrm{WU}$; ๆ: combined post- and pre-capillary PH with DPG $\geqslant 7 \mathrm{mmHg}$ and/or PVR >3 WU.

According to the current definition of the 2015 ESC/ERS guidelines, patients were classified as Ipc-PH (DPG $<7 \mathrm{mmHg}$ and/or PVR $\leqslant 3 \mathrm{WU}, \mathrm{n}=858(57.0 \%)$ ) versus $\mathrm{Cpc}-\mathrm{PH}$ (DPG $\geqslant 7 \mathrm{mmHg}$ and/or PVR $>3 \mathrm{WU}, \mathrm{n}=216(14.3 \%))$. The numbers in bold in table 1 indicate the number of patients with DPG/PVR combinations that are unclassifiable using the current definition $(\mathrm{n}=432(28.7 \%))$.

If one were to reclassify PH-LHD using the definition: Ipc-PH corresponding to DPG $<7 \mathrm{mmHg}$ and PVR $\leqslant 3 \mathrm{WU}$, and Cpc-PH corresponding to DPG $\geqslant 7 \mathrm{mmHg}$ and/or PVR $>3 \mathrm{WU}$, one would get $57 \%$ and $43 \%$ cases, respectively, which does not reflect the clinical observation that only a minority of patients with PH-LHD experience significantly shorter survival [6]. Therefore, we suggest defining Ipc-PH as PH-LHD with a DPG $<7 \mathrm{mmHg}$ and/or PVR $\leqslant 3 \mathrm{WU}$ and Cpc-PH as PH-LHD with a DPG $\geqslant 7 \mathrm{mmHg}$ and PVR $>3$ WU. Under these conditions, $14.3 \%$ of PH-LHD would be classified as Cpc-PH in accordance with our observations in a large patient population [13]. The current proposal should stimulate independent validation in series of PH-LHD from other centres.

$\circ$

@ERSpublications

Pulmonary vascular disease in heart failure comprises increased RV afterload, poor RV-PV coupling and worse survival http://ow.ly/4n622h

Mario Gerges, Christian Gerges and Irene M. Lang

Dept of Internal Medicine II, Division of Cardiology, Vienna General Hospital, Medical University of Vienna, Vienna, Austria.

Correspondence: Irene M. Lang, Dept of Internal Medicine II, Division of Cardiology, Medical University of Vienna, Währinger Gürtel 18-20, 1090 Vienna, Austria. E-mail: irene.lang@meduniwien.ac.at

Received: Jan 222016 | Accepted after revision: March 202016 | First published online: May 122016

Editorial comment in: Eur Respir J 2016; 48: 308-310; 311-314.

Support statement: Supported by educational grants from Actelion Pharmaceuticals Ltd (grant No 00283GMS\&C)., Bayer Healthcare (grant No. 15662) and United Therapeutics Corporation (grant No. REG-NC-002). Funding information for this article has been deposited with FundRef.

Conflict of interest: Disclosures can be found alongside the online version of this article at erj.ersjournals.com

\section{References}

1 Galiè N, Humbert M, Vachiery JL, et al. 2015 ESC/ERS Guidelines for the diagnosis and treatment of pulmonary hypertension: The Joint Task Force for the Diagnosis and Treatment of Pulmonary Hypertension of the European Society of Cardiology (ESC) and the European Respiratory Society (ERS): Endorsed by: Association for European Paediatric and Congenital Cardiology (AEPC), International Society for Heart and Lung Transplantation (ISHLT). Eur Respir J 2015; 46: 903-975.

2 Galiè N, Humbert M, Vachiery JL, et al. 2015 ESC/ERS Guidelines for the diagnosis and treatment of pulmonary hypertension: The Joint Task Force for the Diagnosis and Treatment of Pulmonary Hypertension of the European Society of Cardiology (ESC) and the European Respiratory Society (ERS)Endorsed by: Association for European Paediatric and Congenital Cardiology (AEPC), International Society for Heart and Lung Transplantation (ISHLT). Eur Heart J 2016; 37: 67-119.

3 Provencher $\mathrm{S}$, Herve $\mathrm{P}$, Sitbon $\mathrm{O}$, et al. Changes in exercise haemodynamics during treatment in pulmonary arterial hypertension. Eur Respir J 2008; 32: 393-398.

4 Naeije R, Vachiery JL, Yerly $\mathrm{P}$, et al. The transpulmonary pressure gradient for the diagnosis of pulmonary vascular disease. Eur Respir J 2013; 41: 217-223.

5 Vachiéry JL, Adir Y, Barbera JA, et al. Pulmonary hypertension due to left heart diseases. J Am Coll Cardiol 2013; 62: Suppl., D100-D108.

6 Gerges C, Gerges M, Lang MB, et al. Diastolic pulmonary vascular pressure gradient: a predictor of prognosis in "out-of-proportion" pulmonary hypertension. Chest 2013; 143: 758-766. 
7 Tedford RJ, Beaty CA, Mathai SC, et al. Prognostic value of the pre-transplant diastolic pulmonary artery pressure-to-pulmonary capillary wedge pressure gradient in cardiac transplant recipients with pulmonary hypertension. J Heart Lung Transplant 2014; 33: 289-297.

8 Tampakakis E, Leary PJ, Selby VN, et al. The diastolic pulmonary gradient does not predict survival in patients with pulmonary hypertension due to left heart disease. JACC Heart Fail 2015; 3: 9-16.

9 Dragu R, Rispler S, Habib M, et al. Pulmonary arterial capacitance in patients with heart failure and reactive pulmonary hypertension. Eur J Heart Fail 2015; 17: 74-80.

10 Ibe T, Wada H, Sakakura K, et al. Pulmonary hypertension due to left heart disease: The prognostic implications of diastolic pulmonary vascular pressure gradient. J Cardiol 2016; 67: 555-559.

11 O'Sullivan CJ, Wenaweser P, Ceylan O, et al. Effect of pulmonary hypertension hemodynamic presentation on clinical outcomes in patients with severe symptomatic aortic valve stenosis undergoing transcatheter aortic valve implantation: insights from the new proposed pulmonary hypertension classification. Circ Cardiovasc Interv 2015; 8: e002358.

12 Nichols EL, Rezaee ME, Brown JR. One-year survival in heart failure patients with preserved ejection fraction and isolated post-capillary or combined post- and pre-capillary pulmonary hypertension. Circulation 2015; 132: Suppl. 3, A14302.

13 Gerges M, Gerges C, Pistritto AMA, et al. Pulmonary hypertension in heart failure: epidemiology, right ventricular function and survival. Am J Respir Crit Care Med 2015; 192: 1234-1246.

14 Miller WL, Grill DE, Borlaug BA. Clinical features, hemodynamics, and outcomes of pulmonary hypertension due to chronic heart failure with reduced ejection fraction: pulmonary hypertension and heart failure. JACC Heart Fail 2013; 1: 290-299.

\title{
A retrospective cohort study of patients with pulmonary embolism: the impact of comorbidities on patient's outcome
}

\author{
To the Editor:
}

Despite considerable advances in diagnosis and treatment, pulmonary embolism (PE) remains is an important clinical entity with a high risk of death. Due to pulmonary bed obstruction, PE can result in acute right ventricular failure, a life-threatening condition.

If untreated, acute PE is associated with a significant mortality rate (as high as 30\%) whereas the casefatality ratio of diagnosed and treated PE drops to $8 \%$ [1]. It is well known that comorbidities can affect one or more diseases through several potential aetiological mechanisms of direct causation, associated risk factors, heterogeneity and independence. In particular, in patients with venous thromboembolism (VTE) the presence of comorbidities can hinder clinical assessment and timely diagnoses [2] and exacerbate the risk of recurrence, complications and death [3].

In order to identify the burden of $\mathrm{PE}$, as well as the most common diagnoses associated with hospital admissions for PE, we analysed the hospitalisation data available for Sardinia (Italy) between 2009 and 2011. The secondary aim was to analyse the difference in comorbidity rates between survivors and patients who died. The study was conducted by analysing data from hospital discharge records (HDR; SDO in Italian) featuring the International Classification of Diseases, ninth revision, Clinical Modification (ICD-9-CM) code for PE (415. 1x) over the period 2009-2011 in Sardinia. Data were obtained from the Department of Health and Hygiene of the "Regione Autonoma della Sardegna" (RAS) Sardinian Regional Government. The HDR includes information pertaining to the hospitalisation and discharge of patients, both resident and non-resident in Sardinia, from all public and private hospitals located in this Italian region. All hospitals are required to provide the Department of Health and Hygiene at RAS with this information in electronic format. Information contained in the HDR is encoded according to the ICD-9-CM. It includes patient demographic characteristics, the field of primary diagnosis (defined as the main reason for hospitalisation), up to six fields for secondary diagnoses, hospital identification codes and diagnostic procedures. The Regional Epidemiological Observatory is a Division of the Department of Health and Hygiene at RAS devoted, among other things, to the management of healthcare information for epidemiological purposes.

Data were processed and descriptive statistics provided using MedCalc software (version 13.3.0.0; Ostend, Belgium). Analysis comprised all hospitalisations with $\mathrm{PE}$ as a primary hospital discharge diagnosis from 2009 to 2011. Data were expressed as absolute numbers, percentage and mean \pm SD. The rates were standardised to the Sardinian population between 2009 and 2011. 